\title{
Reverse relationship between drought of mid-latitudes in East Asia and Northwest Pacific tropical cyclone genesis frequency in summer
}

\author{
Jae-Won Choi, , Yumi Cha and Jeoung-Yun Kim
}

\begin{abstract}
This study found that there is a significant negative correlation between summer drought in Korea, China and Japan and the frequency of tropical cyclone (TC) in the subtropical western North Pacific (SWNP) using effective drought index (EDI). The frequency of TCs that affect Korea is low (high) in a year of summer drought (non-drought). As a case study, in 1994 when there is extremely severe summer drought in Korea, there was high frequency of TCs while in 2003 when there was least severe summer drought, the frequency of TCs is the lowest. Changes in the anomalous secondary circulation, namely anomalous upward (downward) flow in the SWNP and anomalous downward (upward) flow in the mid-latitudes of East Asia, are one of the causes of drought (non-drought).
\end{abstract}

Keywords: Effective drought index, Tropical cyclone frequency, Secondary circulation

\section{Background}

In the summer of 1994, East Asia (in particular, the southern part of Korea, middle China and Japan) went through the severest drought in 30 years (WMO 1995). Park and Shubert (1997) argues that the drought in 1994 was caused by two factors: one is the early development of East Asian high caused by the abnormal development of the Eurasian wave coupled with the Tibetan Anticyclone and the other is the failure of influx of water vapor derived from western Pacific and Indian Ocean due to strengthened cyclonic circulation in the subtropical western North Pacific (SWNP). Yoo et al. (2004) link the hot, dry summer of 1994 with the high sea surface temperature in tropical and subtropical western Pacific, which facilitates convection in the region and affects circulation in East Asia in the form of wave train to suppress convection there. Saji et al. (1999) and Guan and Yamagata (2003) attributes the drought in the year to Indian Ocean Dipole (IOD). They demonstrated that strong positive

*Correspondence: choikiseon@daum.net

National Institute of Meteorological Sciences, 33, Seohobuk-ro, Seogwipo, Jeju 63568, Korea
IOD events cause barotropic Rossby wave train pattern to bring an extremely hot and dry summer to East Asia.

In the summer of 2003, in contrast, Korea had the third largest rainfall in 30 years and the most rainy days in the same period. It should be noted that there is much rainfall in August, after the Changma (late June to late July). In that summer, the worst flooding in 20 years happened in the Huaihe River in China, claiming tremendous lives and property (Jin 2006). However, the southern China had less than half of the average rainfall in that summer despite more tropical cyclones (TCs) than the average and, as a result, suffered a lot of natural disasters including intensive heat wave, drought and wild fire (Levinson and Waple 2004). Such a large amount of rainfall in the mid-latitude region of East Asia was caused by the continuous influx of cold air into Korea by the formation of the upper-level cyclone in East Asia. This was due to the Tibetan upper-level anticyclone's failure to expand to East Asia because of insufficient thermal effect caused by over-the-average snowcover in the Tibetan Plateau (Kim et al. 2005).

As shown above, there is a sharp contrast in rainfall between the mid-latitude and low-latitude regions opf 
East Asia. Based on the previous studies, the frequency of TCs in the SWNP may be used as one of indices to determine the intensity of drought in the mid-latitude regions of East Asia since the convective intensity in the SWNP directly affects atmospheric circulation in those regions. However, very few mechanisms have been identified as to why such drought occurs. Most of existing literature cover case study. This is because the causes of drought are multiple and different in time and place (Namias 1983). This study links the summer drought in Korea with the secondary circulation in the meridional direction between SWNP and the mid-latitudes in East Asia. In other words, this study attempts to examine whether there is correlation between the frequency of TCs in the SWNP and the strength of summer drought in Korea and analyze the mechanism on relationship between the two phenomena.

\section{Data and methods}

TC data for 1978-2007 (30 years) from Regional Specialized Meteorological Centers (RSMC)-Tokyo Typhoon Center are used. These data consists of the latitude and longitude and the central pressure and the maximum sustained wind speed (MSWS) of TCs every $6 \mathrm{~h}$.

The difference in the atmospheric circulation for TC activity between non-drought years and drought years is analyzed using the reanalysis data supplied by the National Centers for Environmental Prediction-National Center for Atmospheric Research, including geopotential height, zonal and meridional winds, vertical velocity $(\omega)$ and National Oceanic and Atmospheric Administration interpolated Outgoing Longwave Radiation (OLR) (Kistler et al. 2001).

The effective drought index (EDI) (Byun and Wilhite 1999) is used to determine the intensity of drought quantitatively. Drought can be terminated by heavy rainfall over a short period of time, and the current state of rainfall in the past must be considered in the index. For this reason the EDI is calculated by weighting rainfall in the past according to passage of time (Byun and Lee 2002; Morid et al. 2006; Akhtari et al. 2009). The more negative it is, the severer the drought is. The EDI used in this study has been derived from daily rainfall data collected from 60 weather stations in South Korea, 160 in China, 12 in North Korea, and 51 in Japan for the last 30 years. However, use of a simple EDI average for summer can lead to wrong assessment of drought in the event of heavy rainfall. To solve this problem, this study uses summer average drought severity calculated by averaging all negative EDI values during summer.

Since droughts are generated by a long-term lack of precipitation, it is difficult to define the degree and period of a drought in terms of precipitations. Therefore, it is needed to make an objective definition of the degree and period of a drought using drought indexes where changes of weather factors rather than changes of precipitations are applied. Because PDSI (Palmer 1965), which is most often used, is calculated as a monthly index, it is difficult to diagnose drought on real-time basis. The standardized precipitation index (SPI) (McKee et al. 1993, 1995) has a calculation period different depending on subjective views of researchers so that drought index also is different depending on studies. The EDI takes into consideration all these issues. This index is what summed day-accumulated precipitations along a time function and the usefulness of which has been proved in many studies (Yamaguchi and Shinoda 2002). Hence, this study defined the summer drought using EDI.

The criteria of drought conditions based on EDI standardized values are as follows: 0.0 to -1.0 'dry condition', -1.0 to -2.0 'drought', and values below -2.0 are defined as 'severe drought.' More details can be found in the study of Byun and Wilhite (1999).

Sixty percent of TCs in the SWNP occur in July, August, and September and thus, summer in this study is defined as these 3 months and the data used here are for the same months (Chia and Ropelewski 2002).

To analyze whether a synoptic condition causes an environmental steering for a TC movement, we calculate deep layer (850-200 hPa) mean flows (DLMFs).

\section{Climatological relationship}

Figure 1a shows the time serial for the average drought severity in summer in Korea and the genesis frequency of TCs in the SWNP. It shows that summer drought in Korea kept being severer up to 1994 and then being wetter afterwards. The genesis frequency of TCs in the SWNP displays a similar pattern. The correlation coefficient between these two time series is -0.52 at the $95 \%$ confidence level. This suggests that when there is drought (wet) condition in Korea, the genesis frequency of TCs in the SWNP increases (decreases). Though the relation between the two is not exactly displayed in other years, comparison between 8 years with low drought severity (years whose normalized value is -0.5 or below: 1978, 1982, 1988, 1992, 1994, 1995, 1996, and 2001) and another 8 years with high drought severity (whose normalized value is 0.7 or higher: 1979, 1980, 1987, 1990, 1998, 2003, 2004, and 2006) reveals that there is a difference of around 40 (135 versus 97) in the genesis frequency of TCs for the two periods. This indicates that there are 5 less TCs occurring in the summer of the latter 8 years. In summer of 1994 when Korea suffered the severest drought, there are 21 TCs, 7 more than the 


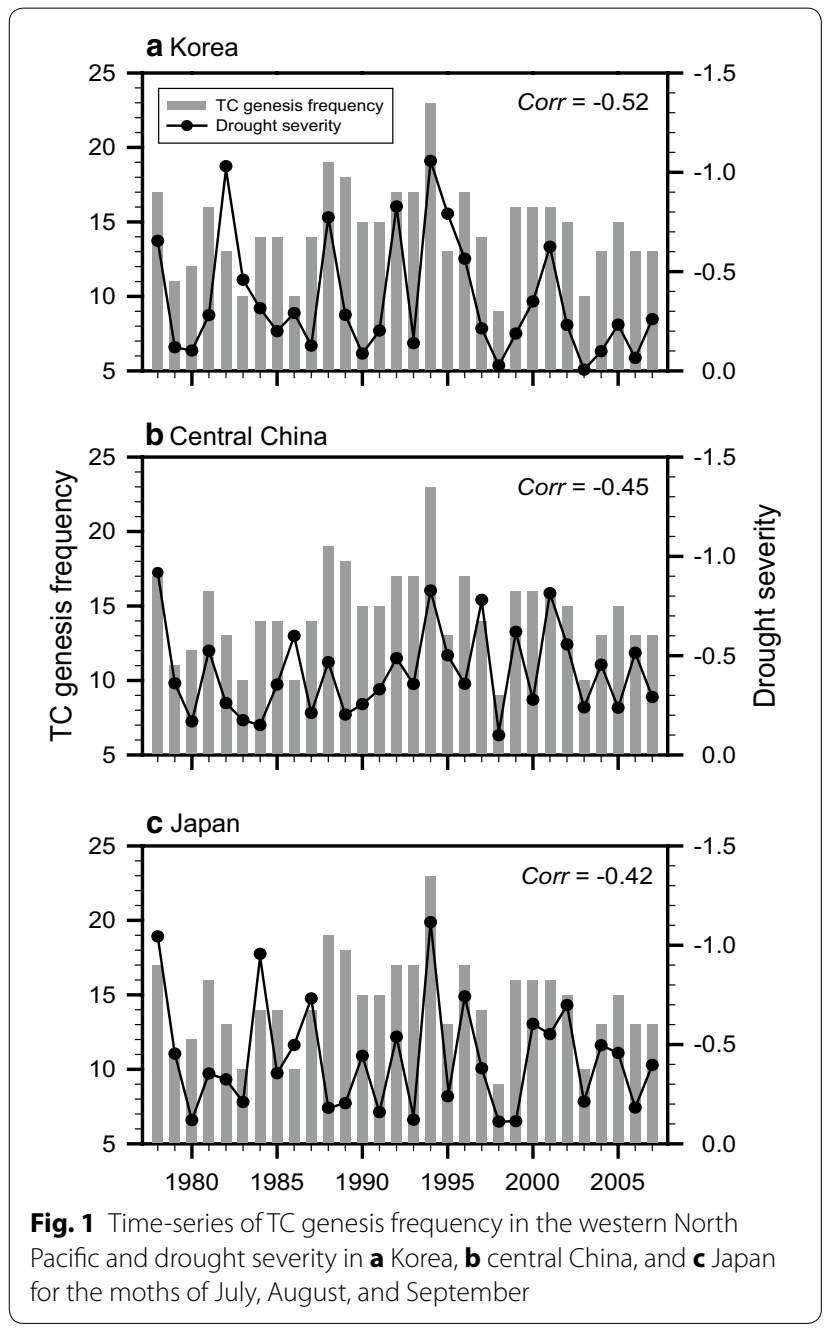

30 year average, 14.5. In summer of 2003 when Korea had much rainfall, in contrast, there are only 10 TCs (5 less than the 30 year average), which are 10 less than the figure of 1994. The following sections will explore the differences in atmospheric circulations between drought years and non-drought years based on these 2 years. The year 1998 has the second weakest drought next to 2003 but has one less TC than 2003, showing strong negative relation. However, the summers of 1994 (Niño-3.4 index: 0.49 ) and 2003 (Niño-3.4 index: 0.44) are normal while that of 1998 (Niño-3.4 index: -0.74) is a strong La Niña phase. Because El Niño/La Niña exerts a strong influence on global-scale atmospheric circulation, simultaneous consideration of La Niña summer and drought summer may increase the difficulty in understanding the mechanism of linkage between drought over Korea and the genesis frequency of TCs in the SWNP. For this reason, the case of 1998 was excluded from the analysis.

\section{TC movement}

The left panel of Fig. 2 shows the difference in the average TC passage frequency between the drought years and non-drought years in each $5^{\circ} \times 5^{\circ}$ grid box (Fig. 2a) and the tracks of all TCs in the summer of 1994 (Fig. 2b) and 2003 (Fig. 2c), respectively.

For climatological difference, TCs tend to affect Korea and Japan from the sea east of the Philippines via East China Sea in the non-drought years. In the drought years, they tend to move from South China Sea via the mainland China to Manchuria or in the east of the main passage in the non-drought years. This indicates that it is hard for the drought to return to the normal by TC in a drought year. However, it is not clear from this study whether the non-drought years are caused by TCs or not. In this regard, Kim and Byun (2006) showed that the rainfall brought by TCs that affected Korea in summer drought years cannot be helpful in easing the drought.

In 1994, there are 6 TCs that affected Korea and two of them pass through it (left in Fig. 2b), but the year is recorded as having the worst summer drought during the analysis period of 30 years. In 2003, a non-drought year, however, there are only two TCs affecting Korea and one hitting it. The other TCs fail to go $\rho$ over $30^{\circ} \mathrm{N}$ and move northwest to southern China or Indochina Peninsula and then get dissipated. This means that there are other causes than TCs for the severe summer drought in 1994 and the non-drought in 2003 along with the result of the climatological difference.

To find out whether the negative relationship between summer drought in Korea and the genesis frequency of TCs in the SWNP is specific to Korea, the difference in drought severity between drought years and non-drought years in Korea and the anomaly of the summer mean drought severity for the 1994 and 2003 are analyzed for each weather station in East Asia (right in Fig. 2). With regard to the climatological difference, negative values are distributed in the regions from central China to Korea and Japan. This indicates that these regions have severer drought in a drought year. In 1994, a drought year, the negative-valued region of central China is narrower at $30^{\circ}-35^{\circ} \mathrm{N}$, but it is similar to the spatial distribution for the climatological mean difference between drought and non-drought years. The year 2003, a non-drought year, shows a spatial distribution opposite to the climatological mean difference rather than in 1994. As discussed above, there is a contradicting rainfall pattern between the midlatitude regions and the low-latitude regions in East Asia. To confirm the negative relationship between summer drought in East Asia and the genesis frequency of TCs in the SWNP, the correlation between the two variables 

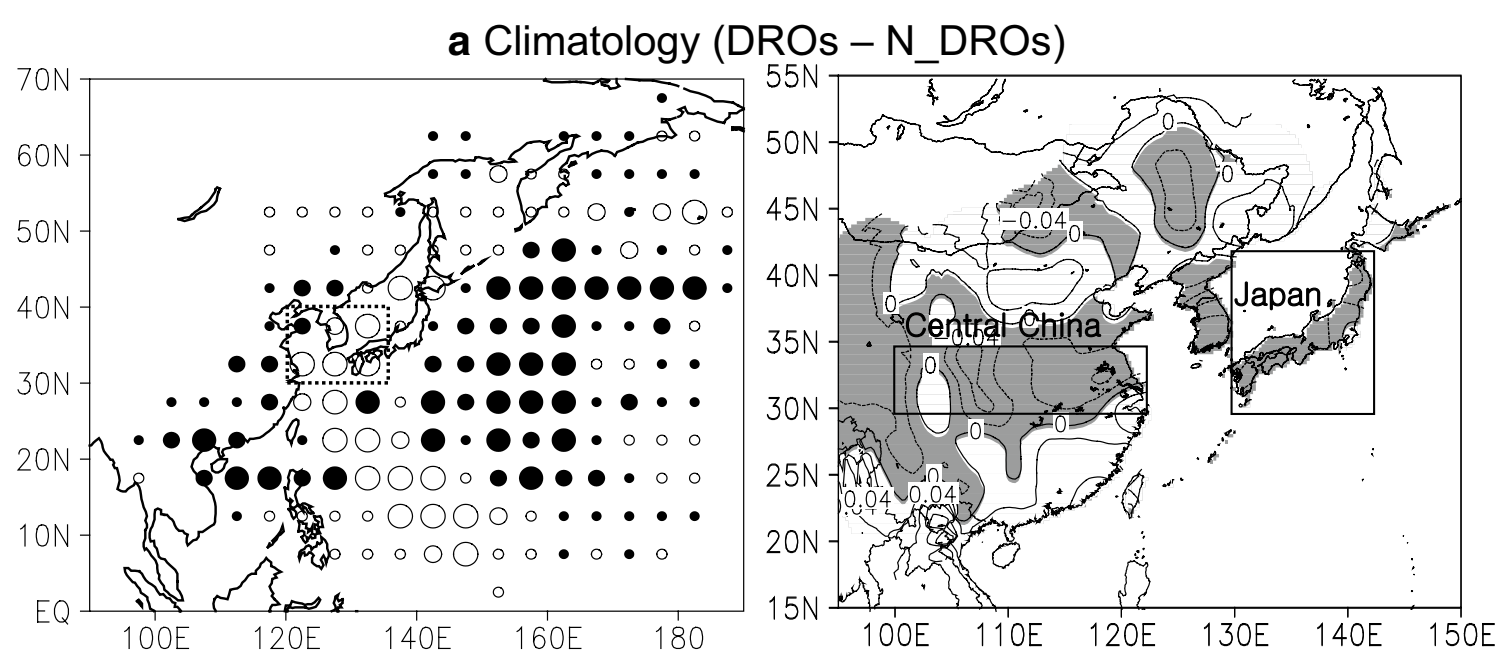

b DRO case (1994)
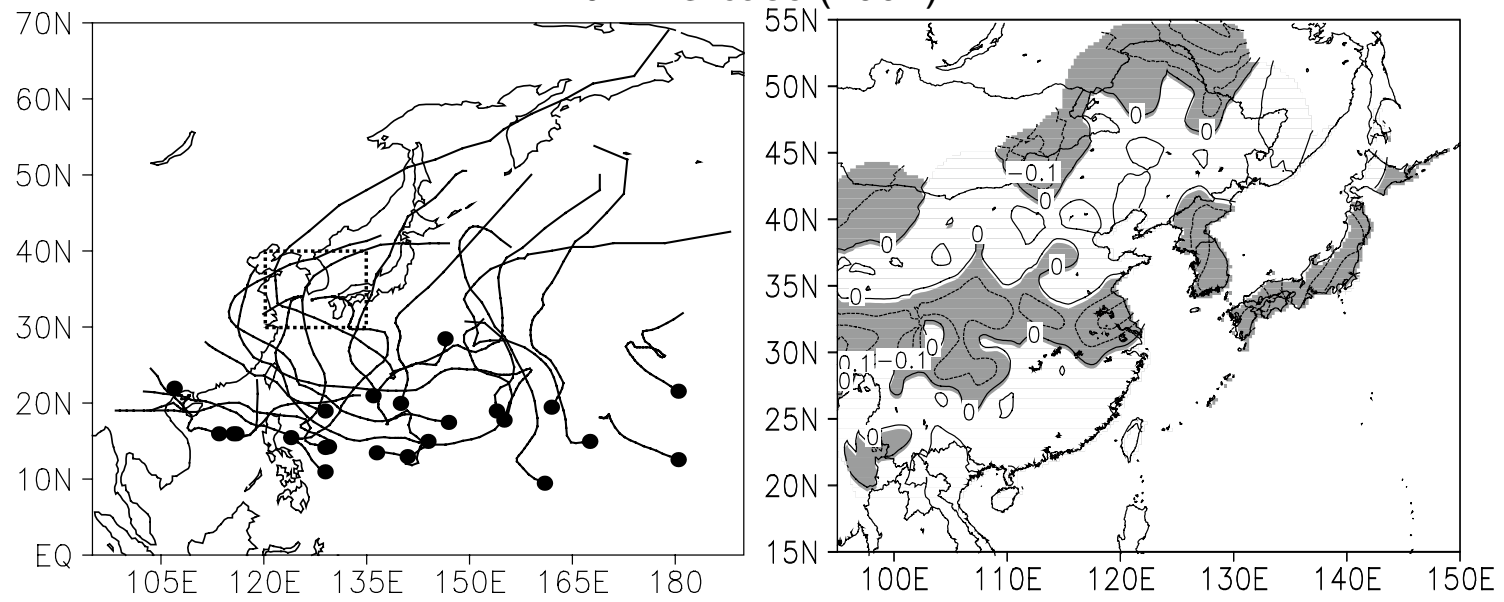

c N_DRO case (2003)
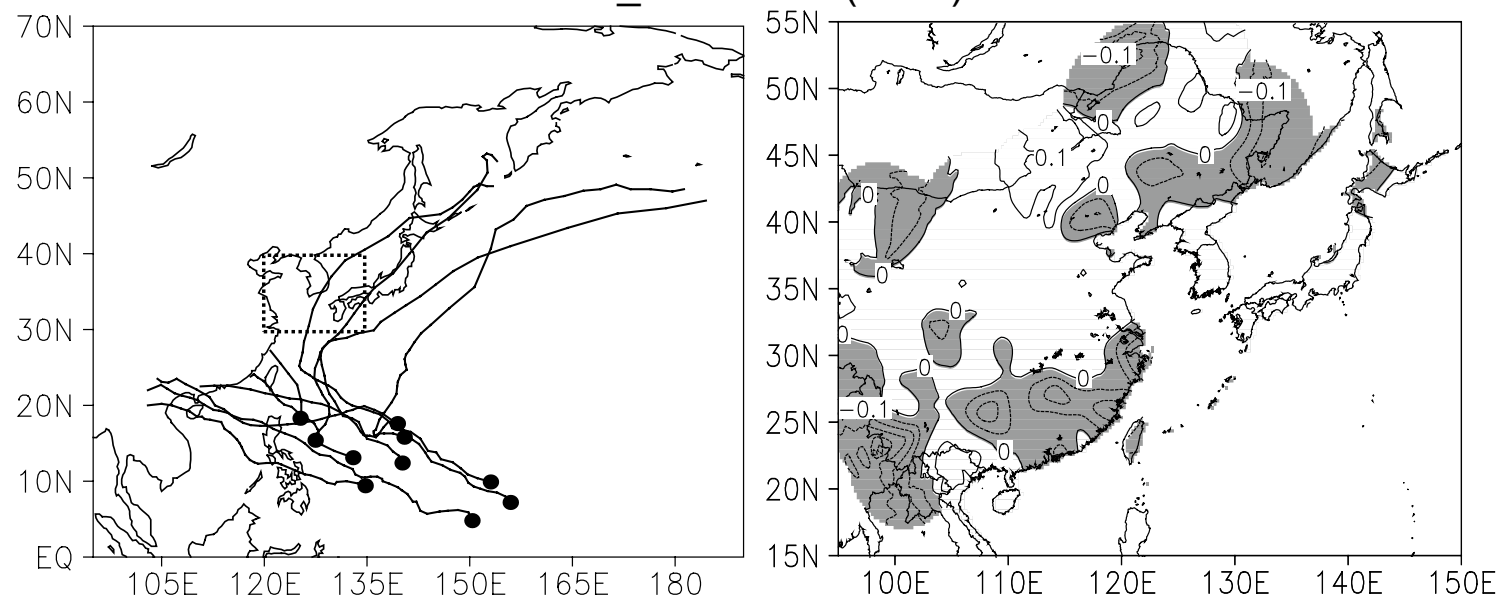

Fig. 2 a TC passage frequency (left) and drought severity (right) difference between drought cases and non-drought cases and TC tracks (left) and drought severity anomalies (right) of (b) drought case year (1994) and c non-drought case year (2003) during the summer. In the left panel of $\mathbf{b}$ and c, dots denote TC genesis locations. In the right panel, shaded areas denote negative values 
is analyzed for the central China $\left(30^{\circ}-35^{\circ} \mathrm{N}, 100^{\circ}-120^{\circ} \mathrm{E}\right.$; Fig. 2a) and Japan (Figs. 1b, c, 2a). The result is -0.4 , which is significant at the $95 \%$ confidence level, though not as high as the correlation coefficient for Korea.

\section{Influence of large-scale atmospheric circulation on drought over East Asia}

A synoptic background for the difference in the movement of TCs between the drought years and the nondrought years is explored using DLMFs (Fig. 3). With respect to the difference in climatological average, there are anomalous anticyclonic circulation in $40^{\circ}-50^{\circ} \mathrm{N}$ east of $105^{\circ} \mathrm{E}$ and anomalous cyclonic circulation in the southeast of Korea. Because of these two anomalous circulations, regions from Korea show anomalous to the eastern part of mainland China are under the influence of northeasterly and easterly. This anomalous easterly in a drought year causes TCs to move from South China Sea to Manchuria via the eastern part of mainland China. In addition, since there are anomalous southerly between the anomalous cyclonic circulation in the southeast of Japan and the anomalous anticyclonic circulation in the northeast of Japan, TCs in drought years also follow this passage.

In 1994, a drought year, there are anomalous cyclonic circulation on the south side of $30^{\circ} \mathrm{N}$ and anomalous anticyclonic circulation on the north. Due to these two circulations, Korea is under the influence of anomalous easterly. In 2003, in contrast, the locations are the other way around from 1994, meaning that the spatial distribution for the climatological difference seems to be upside down. Southeasterly derived from the anomalous anticyclone centered around $30^{\circ} \mathrm{N}$ and $120^{\circ} \mathrm{E}$ is prevalent in southern China. This current, as shown above, causes more than half of TCS occurring in that summer to move northwest. This indicates that 1994, a drought year, has more favorable atmospheric environment to have TCs move toward Korea than 2003.

On the other hand, there are common features in the difference in the climatological average between drought years and the non-drought years and the anomalous field of 1994, a drought year. It is that the meridional atmospheric circulation patterns on each side of $30^{\circ} \mathrm{N}$ contrast sharply. In the drought year, there are anomalous anticyclonic circulation on the north of $30^{\circ} \mathrm{N}$ and anomalous cyclonic circulation on the south. It was already confirmed above that the locations of the anomaly circulations are the other way around in 2003, a non-drought year. This reflects that the change of the meridional atmospheric circulations in the drought years and the non-drought years based on $30^{\circ} \mathrm{N}$ can cause drought and non-drought in Korea, central China and Japan.

The meridional distributed wave pattern shown in the Fig. 3a is a common feature generally observed in the

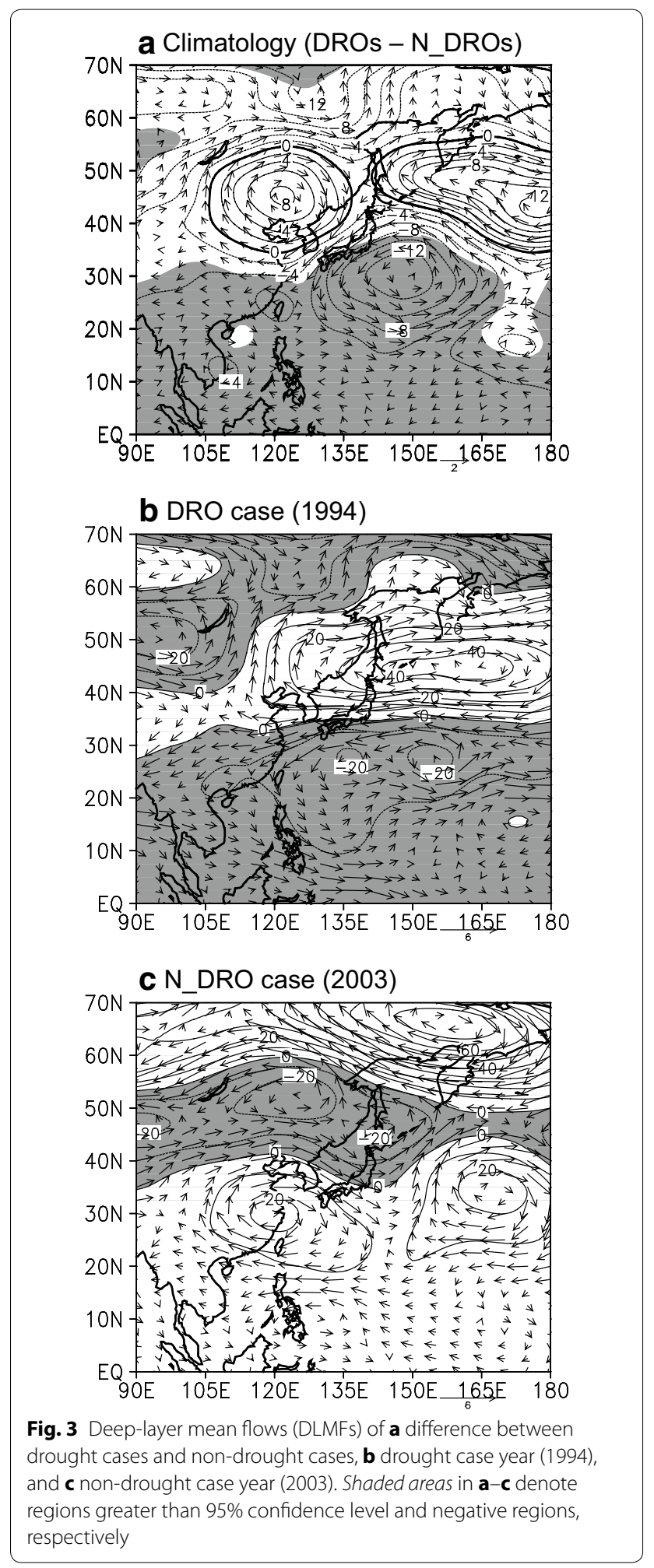

composite between the strong and weak western North Pacific summer years. The dominant factor response for the drought in the Korea, central China, and Japan may be the western North Pacific monsoon. Moreover, the 
TC genesis frequency in the SWNP is highly correlated with the western North Pacific summer monsoon (Chen et al. 2004; Choi et al. 2010; Wu et al. 2012). Therefore, this study examines the relationship between the western North Pacific monsoon index (WNPMI, Wang and Fan 1999) and the drought severity in Korea, central China, and Japan (Fig. 4). The drought severity in three regions is negatively correlated to the WNPMI. This result indicates that when the western North Pacific monsoon is strong (weak), drought condition becomes severe (weak) in three regions. This negative correlation is stronger in Central China and Japan and correlation coefficients between the two variables in two regions are significant at the $95 \%$ confidence level. However, the negative correlation in Korea is not significant statistically.

In addition, we analyze the difference between the summer drought years and the non-drought years of Korea and the anomalies in 1994 and 2003 for OLR (left in Fig. 5). In climatological mean difference and 1994, a drought year, there are positive values in Korea, central China and Japan while there are negative values in the SWNP. This indicates that central China, Korea and Japan belong to an inactive convection area and convection is active in the SWNP (which is related to the increase of TC genesis frequency). In 2003, a non-drought year, in contrast, high positive values are dominant in the
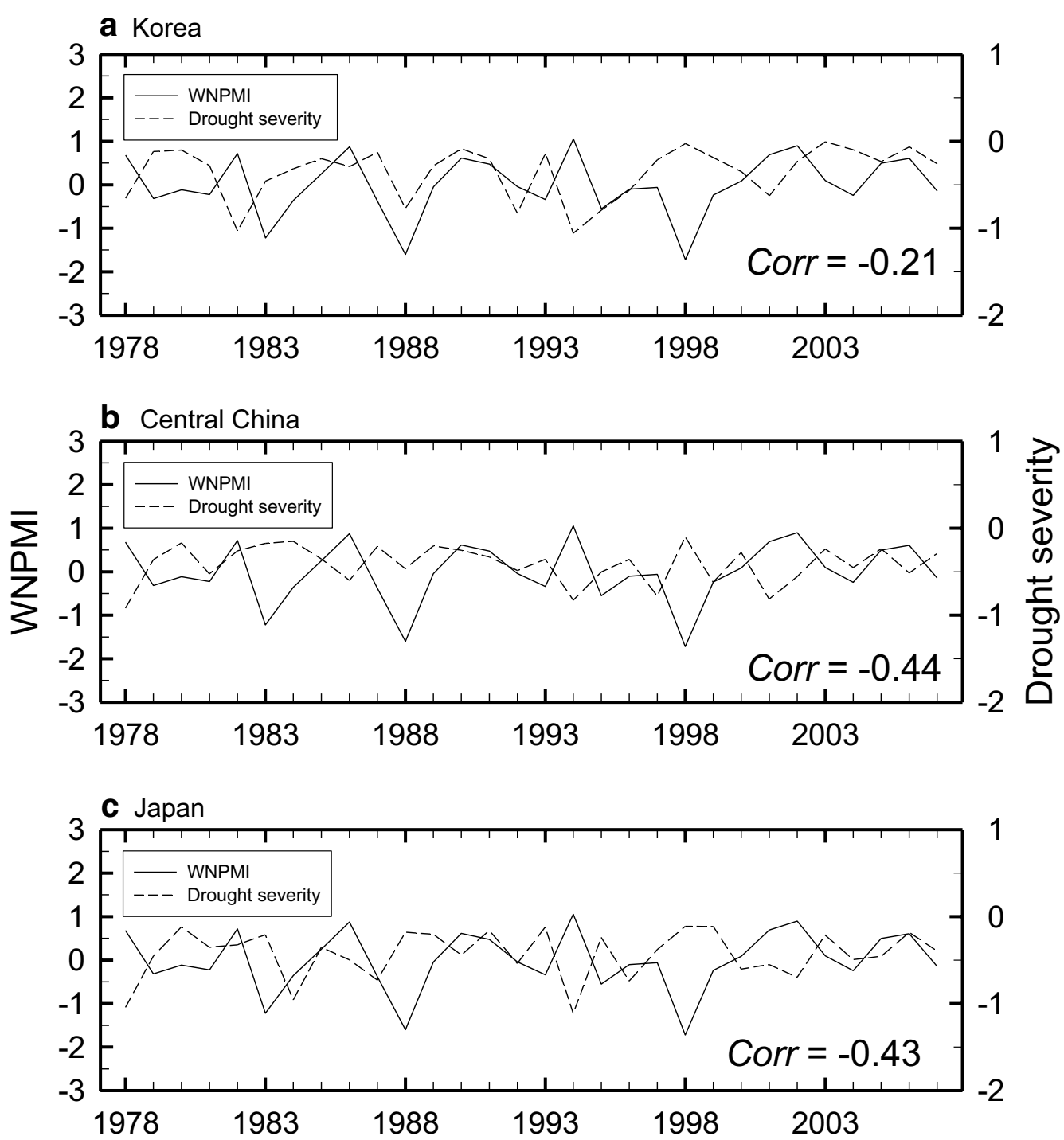

Fig. 4 Time-series of western North Pacific monsoon index (solid line) and drought severity (dashed line) in a Korea, b central China, and c Japan for the moths of July, August, and September 


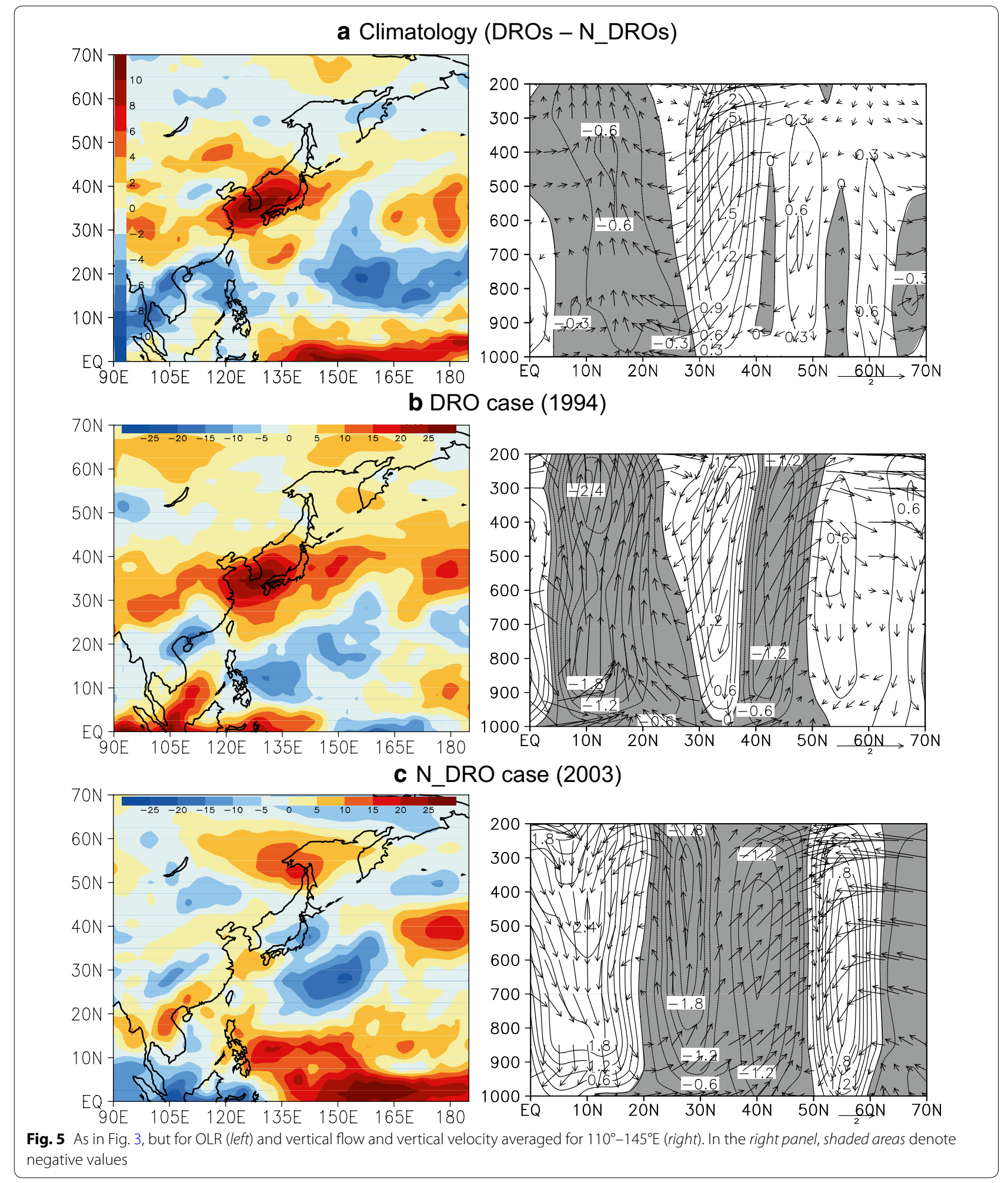

tropical and subtropical western Pacific while low positive or even negative values are shown the mid-latitude regions of East Asia.
The difference in horizontal atmospheric circulations between drought years and the non-drought years is related to the meridional vertical atmospheric circulation. 
The right figure in Fig. 5 shows the climatological mean difference between the drought and non-drought years and the anomalies in 1994 and 2003 for the meridional vertical atmospheric circulation averaged along $100^{\circ}-$ $145^{\circ} \mathrm{E}$. Here, central China, Korea and Japan lie in the longitude band of $110^{\circ}-145^{\circ} \mathrm{E}$. In climatological mean difference and 1994, a drought year, there are an anomalous upward flow on the south of $30^{\circ} \mathrm{N}$ and anomalous downward flow on the north. In other words, anomalous flow that rises in the SWNP descends over $30^{\circ}-40^{\circ} \mathrm{N}$. In 2003, a non-drought year, the phenomenon reverses. It means that there is anomalous secondary circulation between the low and mid-latitudes in East Asia. This is one of the factors that cause drought or non-drought in summer in the mid-latitude regions of East Asia and TC genesis in the SWNP. Meanwhile, no circulation relation seems to exist between the mid-latitude and high latitude regions of East Asia.

\section{Summary and conclusions}

This study identifies the correlation between summer drought in Korea and the genesis frequency of TCs in the SWNP using the EDI for the latest 30 years and analyzes the mechanism between them briefly. There is a negative relation that severe summer drought in Korea is linked with low genesis frequency of TCs in the SWNP (corr $=-0.52$ ). Of the 30 years analyzed, we select 1994 which suffered the severest summer drought and 2003 which had the least severe summer drought to compare them with the climatological mean difference between drought years and non-drought years. Climatologically, more TCs affect Korea in a non-drought year, but in 1994, a drought year, more TCs affect than in 2003, a non-drought year. Despite such a fact, TCs in that summer do not help Korea ease drought.

In drought years, anticyclonic circulation develops northwest of Korea, intensifying northerly and northeasterly from Korea to the eastern part of mainland China while cyclonic circulation develops southeast of Japan to intensify southerly in the SWNP. This causes TCs to move from South China Sea via the eastern part of the mainland China to Manchuria or along the coast of East Asia. In 1994, Korea is under much influence of TCs because there is an anomalous easterly caused by anomalous cyclonic circulation on the south side of $30^{\circ} \mathrm{N}$ and anomalous anticyclonic circulation on the north. In 2003, the pattern is the opposite from 1994. Half of the TCs occurring in that summer moved northwest to South China or Indochina. Consequently, there are contradicting meridional atmospheric circulation pattern based on $30^{\circ} \mathrm{N}$ in East Asia between drought years and nondrought years. This is verified from OLR analysis as well. There are clear positive OLR anomalies in Korea, central
China and Japan and negative anomaly in the SWNP. Such horizontal atmospheric circulation in drought years is related to vertical atmospheric circulation. When Korea has a summer drought year, there is secondary circulation where anomalous upward flow is strengthened in the SWNP (increase of TC genesis) while anomalous downward flow is developed in the mid-latitude regions of East Asia.

\section{Authors' contributions}

JWC designed and carried out the study, and wrote the paper. YC provided detailed information on East Asian meteorological data. JYK acquired and processed the data of YC. JWC, YC, and JYK contributed extensively to the scientific discussion. All authors read and approved the final manuscript.

\section{Acknowledgements}

This work was supported by the R\&D Project of the Korea Meteorological Administration "Development and application of technology for weather forecast" (Grant No: NIMR-2013-B-1).

\section{Competing interests}

The authors declare that they have no competing interests.

Received: 18 August 2016 Accepted: 15 October 2016

Published online: 03 November 2016

\section{References}

Akhtari R, Morid S, Mahdian MH, Smakhin V (2009) Assessment of areal interpolation methods for spatial analysis of SPI and EDI drought indices. Int J Climatol 29:135-145

Byun HR, Lee DK (2002) Defining three rainy seasons and the hydrological summer monsoon in Korea using available water resources index. J Meteor Soc Japan 80:33-44

Byun HR, Wilhite DA (1999) Objective quantification of drought severity and duration. J Clim 12:2747-2756

Chen TC, Wang SY, Yen MC, Gallus WA Jr (2004) Role of the monsoon gyre in the interannual variation of tropical cyclone formation over the western North Pacific. Weather Forecast 19:776-785

Chia HH, Ropelewski CF (2002) The interannual variability in the genesis location of tropical cyclones in the Northwest Pacific. J Clim 15:2934-2944

Choi KS, Wu CC, Cha EJ (2010) Change of tropical cyclone activity by PacificJapan teleconnection pattern in the western North Pacific. J Geophys Res 115:D19114. doi:10.1029/2010JD013866

Guan Z, Yamagata T (2003) The unusual summer of 1994 in East Asia: IOD teleconnections. Geophys Res Lett 30:1544-1547

Jin, RH, Jiao MY, Xu J, Qui HF (2006) Characteristics and cause analysis of Western Pacific subtropical high with the Huaihe River floods in 2003. Second Korea-Japan-China Joint Conference on Meteorology, pp 146-146

Kim YW, Byun HR (2006) On the causes of summer droughts in Korea and their return to normal. Asia-Pac J Atmos Sci 42:237-251

Kim KO, Park CK, Ahn JN (2005) Characteristics of atmospheric circulation over East Asia and unusual climate of Korea in summer 2003. Asia-Pac J Atmos Sci 41:519-532

Kistler R, Collins W, Saha S, White G, Woollen J (2001) The NCEP/NCAR 50-year reanalysis. Bull Am Meteor Soc 82:247-267

Levinson DH, Waple AM (2004) State of the climate in 2003. Bull Am Meteor Soc 85:881

McKee TB, Doesken NJ, Kleist J (1993) The relationship of drought frequency and duration to time scales. Proceedings of the 8th conference of applied climatology, 17-22 January 1993. American Meteorological Society, Anaheim, pp 179-184

McKee TB, Doesken NJ, Kleist J (1995) Drought monitoring with multiple time scales. Proceedings of the 9th conference on applied climatology, 15-20 January 1995. American Meteorological Society, Dallas, pp 233-236 
Morid S, Smakhtin V, Moghaddasi M (2006) Comparison of seven meteorological indices for drought monitoring in Iran. Int J Climatol 26:971-985

Namias J (1983) Some causes of United States drought. J Appl Meteor 2:30-39 Palmer WC (1965) Meteorological drought. US Weather Bureau Research Paper 45

Park JK, Shubert SD (1997) On the nature of the 1994 East Asian summer drought. J Clim 10:1056-1070

Saji NH, Goswami BN, Vinayachandran PN, Yamagata T (1999) A dipole mode in the tropical Indian Ocean. Nature 401:360-363

Wang B, Fan Z (1999) Choice of South Asian summer monsoon indices. Bull Am Meteor Soc 80:629-638
World Meteorological Organization (1995) WMO statement on the status of the global climate in 1994. WMO-No. 826, World Meteorological Organization, Geneva, Switzerland, p 20

Wu L, Wen Z, Huang R, Wu R (2012) Possible linkage between the monsoon trough variability and the tropical cyclone activity over the Western North Pacific. Mon Weather Rev 140:140

Yamaguchi Y, Shinoda M (2002) Soil moisture modeling based on multiyear observations in the Sahel. J Appl Meteor 41:1140-1146

Yoo SH, Ho CH, Yang S, Choi HJ, Jhun JG (2004) Influences of tropical western and extratropical Pacific SST on East and Southeast Asian climate in the summers of 1993-94. J Clim 17:2673-2687

\section{Submit your manuscript to a SpringerOpen ${ }^{\circ}$ journal and benefit from:}

- Convenient online submission

- Rigorous peer review

- Immediate publication on acceptance

- Open access: articles freely available online

- High visibility within the field

- Retaining the copyright to your article 